\title{
Excessive Consumption of Green Tea as a Risk Factor for Periodontal Disease among Korean Adults
}

\author{
Kyungdo Han ${ }^{1}$, Eunkyung Hwang ${ }^{2}$ and Jun-Beom Park ${ }^{3, *}$ \\ 1 Department of Biostatistics, College of Medicine, The Catholic University of Korea, Seoul 06591, Korea; \\ hkd917@naver.com \\ 2 Bangmok College of General Education, Myongji University, Seoul 03674, Korea; hwangek@mju.ac.kr \\ 3 Department of Periodontics, College of Medicine, The Catholic University of Korea, Seoul 06591, Korea \\ * Correspondence: jbassoonis@yahoo.co.kr; Tel.: +82-10-4325-2651
}

Received: 20 April 2016; Accepted: 29 June 2016; Published: 2 July 2016

\begin{abstract}
This study was performed to assess the relationship between the amount of green tea that is consumed and periodontitis. It is based on data obtained from the Korea National Health and Nutrition Examination Survey, conducted between 2008 and 2010. A community periodontal index equal to code 3 was defined as moderate periodontitis, and code 4 was defined as severe periodontitis $(n=16,726)$. Consumption of green tea less than one cup per day was associated with a decreased prevalence of periodontal disease among Korean adults. The association between the consumption of green tea and periodontal disease was independent of various potential confounding factors, such as age, sex, body mass index, smoking, drinking, exercise, metabolic syndrome, frequency of tooth brushing per day, use of secondary oral products, the number of dental examination per year, diabetes, hypertension, and white blood cell count. Adjusted odds ratio and 95\% confidence interval of no consumption was $1.360(1.156,1.601)$ when participants with consumption of two times per week $\leqslant x<7$ times per week was considered as a reference. However, consumption of one or more cups per day increased the prevalence of moderate and severe periodontitis. In conclusion, excessive consumption of green tea may be considered as a risk factor for periodontal disease among Korean adults.
\end{abstract}

Keywords: epidemiology; health surveys; nutrition surveys; oral health; periodontitis; tea

\section{Introduction}

Green tea is a currently popular beverage and the use of green tea extracts as dietary supplements for a wide range of applications is increasing due to its health-promoting effects [1]. Green tea contains polyphenols (the major component in green tea), which represent a cluster known as catechins [2]. Catechins are reported to exhibit antioxidant, antimicrobial, anticollagenase, antimutagenic, and chemopreventive properties [3]. Among the polyphenols, epigallocatechin gallate and epicatechin gallate are the most predominant catechins [3]. It is reported that the consumption of green tea reduced the risk of many modern diseases [4]. Green tea has shown a preventive effect against cancer and cardiovascular disease in experimental and epidemiologic studies and within other physiological functions, such as an anti-hypertensive effect, body weight control, antibacterial and antivirasic activity, solar ultraviolet protection, bone mineral density increase, anti-fibrotic properties, and the provision of neuroprotective power [5-7].

Moreover, growing evidence suggests a beneficial role of green tea in oral health [8,9]. It has been reported that green tea protects against bacterial-induced dental caries [8]. One previous report showed the association between the consumption of green tea and periodontal disease [10,11]. Green tea extract inhibited the onset of periodontal destruction (loss of attachment and alveolar bone resorption) in experimental periodontitis among rats [10]. Previous reports regarding human participants showed 
that there was a modest inverse association between the intake of green tea and periodontal disease [11]. However, the effects of the amount of green tea that is consumed and periodontal disease is not well documented. It was hypothesized that there was no significant association between the amount of green tea consumed and periodontal disease. Thus, using nationally representative data, this study was performed to assess the relationship between the amount of green tea consumed and the incidence of periodontitis.

\section{Materials and Methods}

\subsection{Overview of the Survey and Participants}

This study was based on data obtained from the Korea National Health and Nutrition Examination Survey (KNANES), which was conducted between 2008 and 2010 by the Division of Chronic Disease Surveillance under the Korea Centers for Disease Control and Prevention and the Korean Ministry of Health and Welfare. KNHANES surveys are conducted annually by using a rolling sampling design that involves a complex, stratified, multistage probability-cluster survey of a large representative sample of the non-institutionalized civilian population in South Korea. The present cross-sectional analysis was restricted to adult participants $\geqslant 19$ years of age that completed the health examination assessment and the nutrition survey, having no missing values for the consumption of green tea or outcome variables. Initially, 29,235 total participants were screened, and the 7424 subjects aged $<19$ were excluded. After removing 5085 subjects who had missing parameters, 16,726 total subjects were included. The consumption of green tea, carbonated beverages, and coffee was calculated according to the survey. Information regarding age, residence area, income, occupation, education, exercise, smoking history, and alcohol intake was collected during the health interview. All the individuals provided written informed consent. This study was approved by the Institutional Review Board of the Korean Center for Disease Control and Prevention and conducted according to the Helsinki Declaration-based Ethical Principles for Medical Research Involving Human Subjects.

Trained inspectors obtained the anthropometric evaluation. Body weight and height were measured to the nearest $0.1 \mathrm{~kg}$ and $0.1 \mathrm{~cm}$, respectively, with participants wearing light indoor clothing without shoes. Body mass index was calculated as body weight $(\mathrm{kg})$ divided by the squared height $\left(\mathrm{m}^{2}\right)$, and waist circumference was measured at the narrowest point between the lower border of the ribcage and the iliac crest in a standing position. Income level was categorized into four quartile groups, the lowest of which included households with a monthly income of $<\$ 1092.40$ USD [12]. The participants' education level was categorized into two groups: below high school and high school graduates or above. Smoking status was divided into two categories: current smoker or not. Smoking status was defined according to self-reported cigarette use and based on current smoking habits [13]. Alcohol consumption was assessed by asking the participants about their drinking behavior during the month prior to the interview. The responses were converted into the amount of pure alcohol (in grams) consumed per day by using the average number of alcoholic beverages consumed and the frequency of alcohol consumption. Alcohol consumption status was categorized into three groups according to average daily alcohol consumption: nondrinkers, and light to moderate (1-30 g), and heavy (>30 g) drinkers [14]. Regular exercise was defined as engaging in a moderate fitness activity on a regular basis for $\geqslant 30 \mathrm{~min}$ at a time, at least five times per week, or for $\geqslant 20 \mathrm{~min}$ at a time at least three times per week in a vigorous fitness activity. Daily energy, fat, protein, and calcium intake were calculated using a food database developed for the KNHANES and the food composition table published by the National Rural Living Science Institute under the Rural Development Administration.

\subsection{Biochemical Measurements and the Definition of Metabolic Syndrome}

To measure concentrations of serum-fasting plasma glucose and high-density lipoprotein cholesterol and white blood cell count, a blood sample was collected from the antecubital vein of each participant after he or she fasted for more than $8 \mathrm{~h}$. Blood samples were analyzed within 
$24 \mathrm{~h}$ of transportation. Levels of serum-fasting plasma glucose, total cholesterol, triglycerides, and high-density lipoprotein cholesterol were measured with a Hitachi Automatic Analyzer 7600 (Hitachi, Tokyo, Japan) by enzymatic methods using commercially available kits (Daiichi, Tokyo, Japan). White blood cell count was measured from the blood sample.

A standard mercury sphygmomanometer (Baumanometer, W.A. Baum Co., Copiague, NY, USA) was used to acquire a blood pressure measurement. Systolic blood pressure and diastolic blood pressure were measured twice at five-minute intervals, and the average values were used for the analysis.

Metabolic syndrome was defined according to the American Heart Association/National Heart, Lung, and Blood Institute Scientific Statement criteria for Asians [15,16]. Diabetes is defined as fasting blood sugar greater than $126 \mathrm{mg} / \mathrm{dL}$ or when the individual was currently using anti-diabetic medications [17]. Hypertension was defined as an average BP of $\geqslant 140 / 90 \mathrm{mmHg}$ or if the individuals were taking antihypertensive medication $[18,19]$.

\subsection{Periodontal Treatment Needs and Oral Health Behaviors}

The frequency of daily tooth brushing was measured by the total number of times the teeth were brushed per day. Dental checkup within a year, self-reported oral status, chewing ability, and speech were evaluated.

The World Health Organization's community periodontal index (CPI) was used to assess periodontal treatment needs and defined periodontal disease. All teeth of each subject were divided into sextants. Ten specific index teeth $(17,16,11,26,27,36,37,31,46$, and 47) were examined to evaluate each sextant's score. A sextant was only scanned if two or more teeth were present. If index teeth were absent from a sextant, all of the remaining teeth were examined to produce the score, and the highest score was recorded as the score for the sextant. The CPI score represented periodontitis status as follows-0: normal, 1: gingival bleeding, 2: calculus, 3: a shallow pocket with depth of 3.5-5.5 mm or moderate periodontitis, and 4: a deep pocket depth $\geqslant 5.5 \mathrm{~mm}$ or severe periodontitis [20]. A CPI of 3 or 4 was considered as having periodontitis (moderate and severe periodontitis, respectively) [14]. In 2008 KNHANES, 24 trained dentists examined the periodontal status of subjects. Twenty-nine and 36 dentists performed periodontal examination in 2009 and 2010 KNHANES, respectively.

\subsection{Statistical Analyses}

All data are presented as the mean \pm standard error or as a percentage (standard error). Logarithmic transformation was performed to achieve normal distribution when necessary. Student's $t$-test or the chi-square test was used to investigate the differences in the presence of periodontal treatment needs according to the variables. Survey sample weights were used in all analyses to produce estimates that were representative of the non-institutionalized civilian Korean population. A statistical software package (SAS version 9.2 for Windows, SAS Institute, Cary, NC, USA) was used for statistical analysis to account for the complex sampling design. Two-sided $p$ values of $<0.05$ were considered statistically significant. Multiple logistic regression analyses were used to assess the associations of periodontal treatment needs and the consumption of green tea after covariate adjustment. The covariates were age, sex, body mass index, smoking, drinking, exercise, metabolic syndrome, frequency of tooth brushing per day, use of secondary oral products, number of dental examinations within a year, diabetes, hypertension, and white blood cell count.

\section{Results}

Table 1 describes the baseline characteristics of the study individuals according to the presence of periodontal disease. The mean age, body mass index, and waist circumference were significantly higher in participants with periodontal disease. The percentage of individuals with periodontitis was higher in current smokers and drinkers.

Table 2 shows the subgroup analysis regarding the consumption of green tea by oral health. Self-reported oral status showed that the individuals with problems were lowest with the group of 
two times per week $\leqslant x<7$ times per week. The individuals with chewing discomfort were lowest with the group of two times per week $\leqslant x<7$ times per week.

Table 1. Baseline characteristics of study individuals according to severity of periodontal disease.

\begin{tabular}{|c|c|c|c|}
\hline & \multicolumn{3}{|c|}{$\begin{array}{c}\text { Periodontal Disease (Moderate (CPI 3) and } \\
\text { Severe Periodontitis (CPI 4)) }\end{array}$} \\
\hline & No & Yes & $p$-Value * \\
\hline Unweighted $n$ & 11290 & 5436 & \\
\hline Consumption of green tea & & & $<0.0001$ \\
\hline No consumption & $35.2(0.7)$ & $44.8(1)$ & \\
\hline$\leqslant$ Once per month & $15.4(0.4)$ & $13.4(0.6)$ & \\
\hline Two times per month $\leqslant x<2$ times per week & $18.9(0.5)$ & $14.9(0.6)$ & \\
\hline Two times per week $\leqslant x<7$ times per week & $16.2(0.5)$ & $11.9(0.6)$ & \\
\hline$\geqslant$ Once per day & $14.3(0.4)$ & $15(0.7)$ & \\
\hline Age (years) & $40.57 \pm 0.26$ & $52.08 \pm 0.31$ & $<0.0001$ \\
\hline Sex (male) & $45.7(0.5)$ & $59.4(0.7)$ & $<0.0001$ \\
\hline Body mass index $\left(\mathrm{kg} / \mathrm{m}^{2}\right)$ & $23.4 \pm 0.04$ & $24.13 \pm 0.06$ & $<0.0001$ \\
\hline White blood cell $\left(\times 10^{9} / \mathrm{L}\right) * *$ & $5.87(5.91-5.91)$ & $6.21(6.26-6.26)$ & $<0.0001$ \\
\hline Energy intake (kcal/day) & $2015.17 \pm 12.08$ & $1997.59 \pm 17.14$ & 0.3523 \\
\hline Calcium intake (mg/day) & $513.4 \pm 4.28$ & $518.12 \pm 7.45$ & 0.5757 \\
\hline Smoking & $22.7(0.5)$ & $30.8(0.8)$ & $<0.0001$ \\
\hline Drinking & & & $<0.0001$ \\
\hline Non-drinker & $21.8(0.5)$ & $27(0.7)$ & \\
\hline Mild to moderate drinker & $68.9(0.6)$ & $60.7(0.8)$ & \\
\hline Heavy drinker & $9.3(0.4)$ & $12.3(0.6)$ & \\
\hline Exercise (yes) & $24.9(0.6)$ & $26.7(0.8)$ & 0.0417 \\
\hline Income (the lowest quartile) & $13.5(0.6)$ & $19.9(0.8)$ & $<0.0001$ \\
\hline Education (high school graduate or higher) & $78.4(0.6)$ & $55.8(1.2)$ & $<0.0001$ \\
\hline Residence (urban) & $83.1(1.5)$ & $76.2(2.1)$ & $<0.0001$ \\
\hline Occupation (yes) & $61.5(0.6)$ & $65.9(0.9)$ & $<0.0001$ \\
\hline Diabetes & $5.5(0.2)$ & $13.8(0.6)$ & $<0.0001$ \\
\hline Hypertension & $20.8(0.5)$ & $38.9(0.9)$ & $<0.0001$ \\
\hline Metabolic syndrome & $20.2(0.5)$ & $38(0.9)$ & $<0.0001$ \\
\hline Consumption of coffee & & & $<0.0001$ \\
\hline No consumption & $12.9(0.4)$ & $11.1(0.5)$ & \\
\hline$\leqslant$ Once per month & $4.7(0.3)$ & $3.4(0.3)$ & \\
\hline Two times per month $\leqslant x<2$ times per week & $7.7(0.3)$ & $6.4(0.4)$ & \\
\hline Two times per week $\leqslant x<7$ times per week & $13.0(0.4)$ & $10.7(0.5)$ & \\
\hline$\geqslant$ Once per day & $61.7(0.6)$ & $68.4(0.8)$ & \\
\hline Consumption of carbonated beverages & & & $<0.0001$ \\
\hline No consumption & $33.5(0.6)$ & $44.5(1)$ & \\
\hline$\leqslant$ Once per month & $22.9(0.5)$ & $24.3(0.7)$ & \\
\hline Two times per month $\leqslant x<2$ times per week & $25.4(0.5)$ & $20.3(0.7)$ & \\
\hline Two times per week $\leqslant x<7$ times per week & $15.4(0.5)$ & $9.7(0.6)$ & \\
\hline$\geqslant$ Once per day & $2.8(0.2)$ & $1.2(0.2)$ & \\
\hline Frequency of tooth brushing per day & & & $<0.0001$ \\
\hline$\leqslant 1$ & $10(0.4)$ & $15.8(0.7)$ & \\
\hline 2 & $42.4(0.7)$ & $46.5(0.9)$ & \\
\hline$\geqslant 3$ & $47.6(0.7)$ & $37.6(1.0)$ & \\
\hline Use of secondary oral products & $44.2(9.8)$ & $33.0(1.1)$ & $<0.0001$ \\
\hline Dental checkup within a year (yes) & $27.6(0.8)$ & $25.6(0.9)$ & 0.0414 \\
\hline Self-reported oral status & & & $<0.0001$ \\
\hline Favorable & $13.8(0.4)$ & $8.8(0.5)$ & \\
\hline Average & $44.6(0.6)$ & $31.7(0.9)$ & \\
\hline Problematic & $41.6(0.6)$ & $59.5(1)$ & \\
\hline Chewing & & & $<0.0001$ \\
\hline Discomfort & $20.7(0.5)$ & $41.1(0.9)$ & \\
\hline Minor problem & $15.3(0.5)$ & $15.5(0.7)$ & \\
\hline No discomfort & $64(0.6)$ & $43.4(0.9)$ & \\
\hline Speech & & & $<0.0001$ \\
\hline Discomfort & $5.7(0.3)$ & $12(0.5)$ & \\
\hline Minor problem & $6.3(0.3)$ & $9.8(0.5)$ & \\
\hline No discomfort & $88(0.4)$ & $78.1(0.8)$ & \\
\hline
\end{tabular}

Data are presented as mean \pm standard error or percentages (standard error). ${ }^{*} p$ values were obtained by an independent $t$-test for continuous variables or the chi-square test for categorical variables. ${ }^{* *}$ Log transformation was applied to the value, and the geometric mean ( $95 \%$ confidence of interval) is shown. 
Table 2. Baseline characteristics of study individuals according to severity of periodontal disease.

\begin{tabular}{|c|c|c|c|c|c|c|}
\hline Consumption of Green Tea & No Consumption & $\leqslant$ Once per Month & $\begin{array}{c}\text { Two Times per Month } \leqslant x< \\
2 \text { Times per Week }\end{array}$ & $\begin{array}{c}\text { Two Times per Week } \leqslant \mathrm{x}< \\
7 \text { Times per Week }\end{array}$ & $\geqslant$ Once per Day & $p$-Value \\
\hline Frequency of tooth brushing per day & & & & & & $<0.0001$ \\
\hline$\leqslant 1$ & $15.6(0.6)$ & $10.9(0.8)$ & $10.1(0.7)$ & $8.4(0.8)$ & $7.8(0.7)$ & \\
\hline 2 & $46.4(0.8)$ & $47.6(1.2)$ & $42.6(1.1)$ & $38.9(1.3)$ & $38.4(1.3)$ & \\
\hline$\geqslant 3$ & $38(0.8)$ & $41.4(1.3)$ & $47.3(1.2)$ & $52.6(1.3)$ & $53.8(1.3)$ & \\
\hline Dental checkup within a year (yes) & $22.9(0.9)$ & $25.5(1.1)$ & $28.1(1.2)$ & $32.5(1.2)$ & $32.3(1.3)$ & $<0.0001$ \\
\hline Self-reported oral status & & & & & & $<0.0001$ \\
\hline Favorable & $11.1(0.5)$ & $11.3(0.8)$ & $13.9(0.8)$ & $14.8(0.9)$ & $12.3(0.8)$ & \\
\hline Average & $39.4(0.8)$ & $41.6(1.2)$ & $41.7(1.1)$ & $41.3(1.3)$ & $42.3(1.3)$ & \\
\hline Problematic & $49.5(0.9)$ & $47.1(1.2)$ & $44.4(1.2)$ & $43.9(1.3)$ & $45.4(1.3)$ & \\
\hline Chewing & & & & & & $<0.0001$ \\
\hline Discomfort & $32.8(0.8)$ & $23.9(1)$ & $23.1(1)$ & $20.3(1)$ & $24.4(1.2)$ & \\
\hline Minor problem & $14.7(0.6)$ & $15.8(0.9)$ & $15.7(0.9)$ & $15.5(0.9)$ & $16.1(1)$ & \\
\hline No discomfort & $52.5(0.8)$ & $60.2(1.2)$ & $61.3(1.2)$ & $64.2(1.3)$ & $59.5(1.3)$ & \\
\hline Speech & & & & & & $<0.0001$ \\
\hline Discomfort & $10.3(0.5)$ & $6.3(0.6)$ & $6.6(0.5)$ & $5.5(0.5)$ & $5.1(0.5)$ & \\
\hline Minor problem & $8.4(0.4)$ & $7.1(0.7)$ & $6.4(0.5)$ & $6.1(0.6)$ & $7.0(0.7)$ & \\
\hline No discomfort & $81.3(0.6)$ & $86.6(0.8)$ & $87(0.7)$ & $88.4(0.8)$ & $87.9(0.8)$ & \\
\hline
\end{tabular}

Data are presented as percentages (standard error). 
The adjusted odds ratio, 95\% confidence interval and $P$ value of the prevalence of periodontitis in multivariate logistic regression model for the consumption of green tea is shown in Table 3 . The odd ratio ( $95 \%$ confidence intervals) of the prevalence of moderate and severe periodontitis was 1.360 $(1.156,1.601), 1.262(1.047,1.522), 1.092(0.912,1.309), 1$, and $1.375(1.135,1.666)$ for no consumption, $\leqslant$ once per month, two times per month $\leqslant x<2$ times per week, two times per week $\leqslant x<7$ times per week, and $\geqslant$ once per day, respectively (Table 3 ).

Table 3. Adjusted odds ratio, $95 \%$ confidence interval and $P$ value of the prevalence of periodontitis in multivariate logistic regression model for the consumption of green tea.

\begin{tabular}{cccc}
\hline Consumption of Green Tea & Model 1 & Model 2 & Model 3 \\
\hline No consumption & $1.291(1.12,1.488)$ & $1.256(1.086,1.452)$ & $1.359(1.155,1.600)$ \\
$\leqslant$ Once per month & $1.094(0.939,1.275)$ & $1.098(0.939,1.285)$ & $1.264(1.048,1.524)$ \\
Two times per month $\leqslant x<2$ times per week & $1.035(0.891,1.202)$ & $1.03(0.884,1.201)$ & $1.089(0.909,1.304)$ \\
Two times per week $\leqslant x<7$ times per week & 1 & 1 & 1 \\
$\geqslant$ Once per day & $1.31(1.11,1.546)$ & $1.289(1.09,1.525)$ & $1.380(1.139,1.672)$ \\
$P$ for trend & 0.0003 & 0.0019 & 0.00065 \\
\hline
\end{tabular}

Model 1: Age and sex adjusted; Model 2: Model 1 plus body mass index, smoking, drinking and exercise adjusted; Model 3: Model 2 plus metabolic syndrome, frequency of tooth brushing per day, use of secondary oral products and white blood cell adjusted.

\section{Discussion}

This study evaluated the relationship between the amount of green tea consumed and the incidence of periodontitis with nationally representative data. This study showed that consumption of less than one cup of green tea per day was associated with a decrease in the prevalence of periodontal disease among Korean adults. This study has also shown that consumption of one cup or more increased the prevalence of periodontitis. This association between the consumption of carbonated beverages and periodontal disease was independent of various potential confounding factors, such as age, sex, body mass index, smoking, drinking, exercise, metabolic syndrome, frequency of tooth brushing per day, use of secondary oral products, number of dental examination within a year, diabetes, hypertension, and white blood cell count.

Green tea modulates cytokine expression in the periodontium and attenuates alveolar bone resorption in type 1 diabetic rats [21]. In the previous report, green tea intake was reported to reduce the expression of the pro-inflammatory cytokine tumor necrosis factor- $\alpha$ and the osteoclastogenic mediator receptor activator of nuclear factor kappa-B ligand to normal levels, while increasing the expression of the anti-inflammatory cytokine interleukin-10, the osteogenesis-related factor runt-related transcription factor 2, and the anti-osteoclastogenic factor osteoprotegerin [21]. Green tea is shown to inhibit the growth and cellular adherence of bacterial pathogens and their production of virulence factors [11].

Various methods have been applied for the delivery of the green tea extracts. Green tea extract was incorporated into hydroxylpropyl methylcellulose [22,23]. This system showed a bactericidal effect against Gram-negative anaerobic rods and was effective in improving periodontal status. Adjunctive local drug therapy with thermo-reversible sustained-release green tea gel has been shown to reduce inflammation and pockets of the clinical trial in patients with chronic periodontitis [24]. It has been suggested that local drug delivery using green tea extract could be used as an adjunct in the treatment of chronic periodontitis $[22,25,26]$. Green tea has been added to dentifrice in previous studies $[27,28]$. In a previous study, dentifrice containing green tea extracts showed a greater reduction in gingival inflammation and improved periodontal parameters in comparison with fluoride-triclosan dentifrice [28]. Comparative evaluation of the anti-plaque effectiveness of green tea catechin mouthwash was performed with chlorhexidine gluconate; green tea catechin mouthwash $(0.25 \%)$ and chlorhexidine mouthwash $(0.12 \%)$ have shown comparable results in plaque reduction [29]. Collectively, it was suggested that the local delivery of green tea catechin, along with scaling and root planning, is more effective than scaling and root planing alone $[25,26]$. 
This study showed that drinking less than one cup of green tea per day produced beneficial effects on periodontal health. The beneficial effect of the consumption of green tea on periodontitis may be partially explained by the following. The green tea extract of epigallocatechin gallate exerts potent protective effects against oxidative stress, inflammation, protein aggregation, autophagy, and cell death in vitro as well as in vivo [30,31]. Catechin epigallocatechin gallate is reported to destroy established Porphyromonas gingivalis biofilms and inhibit biofilm formation [32,33]. Epigallocatechin gallate is shown to inhibit the production of C-C motif chemokine ligand 11 [34]. Epigallocatechin gallate is shown to diminish cysteine-rich 61 (a potential osteolytic mediator) expression in osteoblasts and, subsequently, reduce macrophage chemotaxis into the lesions by diminishing C-C motif chemokine ligand 2 (a chemokine responsible for macrophage chemotaxis) [9]. In oral epithelial cells and fibroblasts, epigallocatechin gallate showed a neutralizing effect on nicotine-induced toxicity [35]. In a three-dimensional co-culture model of gingival epithelial cells and fibroblasts, epigallocatechin-3-gallate reduced the lipopolysaccharide-induced inflammatory response [36]. Among green tea catechins, epigallocatechin gallate and epicatechin gallate showed the most potent inhibitory effect on collagenase activity when catechins were added to a reaction mixture containing collagenase and collagen [37].

This study has also clearly shown that excessive consumption of green tea increases the risk of periodontitis. The harmful effect of the excessive consumption of green tea on periodontitis may be partially explained by the following. It was reported that a cup of tea contains $15 \mathrm{mg}$ and excessive amounts of green tea consumption will lead to significant amount of caffeine consumption [38]. Caffeine is shown to increase bone loss and enhance the progression of periodontitis [39], and caffeine intake is considered to be one of the possible risk factors for periodontitis [40]. The temperature of the green tea may damage the mucosa or accelerate metabolic reactions, including hastening the absorption of harmful substances in cigarette and alcohol [41]. A previous report has shown that concentrated green tea extract induces severe acute hepatitis and has suggested that such concentrated herbal extracts from green tea may not be free of adverse effects under certain circumstances, including the excessive consumption of green tea [1].

These limitations should be considered. Because of this study's cross-sectional design, the causal direction of the associations between the consumption of green tea and periodontal disease cannot be ascertained [13]. Another limitation of this study is that individual consumption habits were obtained on a recall basis [12]. Other drinks including coffee and carbonated beverages should also be considered for the risk evaluation. However, the data used in this study were collected from the KNHANES, a nationally representative sample, whose participants were recruited using a multi-stage clustered probability design. Further, survey sample weights adjusted for participation rate and response rate were used for all analyses to consider selection bias and to serve as nationally representative data [42]. The association between the consumption of green tea and periodontitis were evaluated using multiple logistic regression analyses after adjusting for confounding factors [13]. Thus, the results from this study can be considered reliable and meaningful to the general audience.

\section{Conclusions}

The results generally indicated a negative association between the consumption of green tea and the risk of periodontal disease among Korean adults. However, the consumption of one or more cups per day increased the risk of moderate and severe periodontitis. In conclusion, the consumption of green tea may be considered an independent risk indicator of periodontal disease among Korean adults, and we suggest that good periodontal health may benefit from moderate consumption of green tea (less than one cup per day).

Acknowledgments: This research was supported by Basic Science Research Program through the National Research Foundation of Korea (NRF) funded by the Ministry of Science, Information and Communication Technology \& Future Planning (NRF-2014R1A1A1003106). 
Author Contributions: K.H., E.H., and J.B. conceived and designed the experiments; K.H., E.H., and J.B. analyzed the data; K.H. and J.B. wrote the paper.

Conflicts of Interest: The authors declare no conflict of interest.

\section{Abbreviations}

The following abbreviations are used in this manuscript:

KNANES Korea National Health and Nutrition Examination Survey

\section{References}

1. Pillukat, M.H.; Bester, C.; Hensel, A.; Lechtenberg, M.; Petereit, F.; Beckebaum, S.; Muller, K.M.; Schmidt, H.H. Concentrated green tea extract induces severe acute hepatitis in a 63-year-old woman-A case report with pharmaceutical analysis. J. Ethnopharmacol. 2014, 155, 165-170. [CrossRef] [PubMed]

2. Ramasamy, C. Potential natural antioxidants: Adjuvant effect of green tea polyphenols in periodontal infections. Infect. Disord. Drug Targets 2015, 15, 141-152. [CrossRef] [PubMed]

3. Venkateswara, B.; Sirisha, K.; Chava, V.K. Green tea extract for periodontal health. J. Indian Soc. Periodontol. 2011, 15, 18-22. [CrossRef] [PubMed]

4. Wierzejska, R. Tea and health-A review of the current state of knowledge. Przegl. Epidemiol. 2014, 68, 595-509.

5. Nugala, B.; Namasi, A.; Emmadi, P.; Krishna, P.M. Role of green tea as an antioxidant in periodontal disease: The Asian paradox. J. Indian Soc. Periodontol. 2012, 16, 313-316. [CrossRef] [PubMed]

6. Gaur, S.; Agnihotri, R. Green tea: A novel functional food for the oral health of older adults. Geriatr. Gerontol. Int. 2014, 14, 238-250. [CrossRef] [PubMed]

7. Cabrera, C.; Artacho, R.; Gimenez, R. Beneficial effects of green tea-A review. J. Am. Coll. Nutr. 2006, 25, 79-99. [CrossRef] [PubMed]

8. Narotzki, B.; Reznick, A.Z.; Aizenbud, D.; Levy, Y. Green tea: A promising natural product in oral health. Arch. Oral Biol. 2012, 57, 429-435. [CrossRef] [PubMed]

9. Lee, Y.L.; Hong, C.Y.; Kok, S.H.; Hou, K.L.; Lin, Y.T.; Chen, M.H.; Wang, C.C.; Lin, S.K. An extract of green tea, epigallocatechin-3-gallate, reduces periapical lesions by inhibiting cysteine-rich 61 expression in osteoblasts. J. Endod. 2009, 35, 206-211. [CrossRef] [PubMed]

10. Yoshinaga, Y.; Ukai, T.; Nakatsu, S.; Kuramoto, A.; Nagano, F.; Yoshinaga, M.; Montenegro, J.L.; Shiraishi, C.; Hara, Y. Green tea extract inhibits the onset of periodontal destruction in rat experimental periodontitis. J. Periodontal. Res. 2014, 49, 652-659. [CrossRef] [PubMed]

11. Kushiyama, M.; Shimazaki, Y.; Murakami, M.; Yamashita, Y. Relationship between intake of green tea and periodontal disease. J. Periodontol. 2009, 80, 372-377. [CrossRef] [PubMed]

12. Han, K.; Ko, Y.; Park, Y.G.; Park, J.B. Associations between the number of natural teeth in postmenopausal women and duration of lactation: The 2010-2012 Korea National Health and Nutrition Examination Survey. Maturitas 2016, 85, 73-78. [CrossRef] [PubMed]

13. Han, K.; Ko, Y.; Park, Y.G.; Park, J.B. Associations between the periodontal disease in women before menopause and menstrual cycle irregularity: The 2010-2012 Korea National Health and Nutrition Examination Survey. Medicine (Baltimore) 2016, 95, e2791. [CrossRef] [PubMed]

14. Park, J.B.; Han, K.; Park, Y.G.; Ko, Y. Association between alcohol consumption and periodontal disease: The 2008 to 2010 Korea National Health and Nutrition Examination Survey. J. Periodontol. 2014, 85, 1521-1528. [CrossRef] [PubMed]

15. Chun, Y.H.; Kim, H.R.; Han, K.; Park, Y.G.; Song, H.J.; Na, K.S. Total cholesterol and lipoprotein composition are associated with dry eye disease in Korean women. Lipids Health Dis. 2013, 12, 84. [CrossRef] [PubMed]

16. Kim, Y.H.; Cho, K.H.; Choi, Y.S.; Kim, S.M.; Nam, G.E.; Lee, S.H.; Ko, B.J.; Park, Y.G.; Han, K.D.; Lee, K.S.; et al. Low bone mineral density is associated with metabolic syndrome in South Korean men but not in women: The 2008-2010 Korean National Health and Nutrition Examination Survey. Arch. Osteoporos. 2013, 8, 142. [CrossRef] [PubMed]

17. Jeon, J.Y.; Ko, S.H.; Kwon, H.S.; Kim, N.H.; Kim, J.H.; Kim, C.S.; Song, K.H.; Won, J.C.; Lim, S.; Choi, S.H.; et al. Prevalence of diabetes and prediabetes according to fasting plasma glucose and HbA1c. Diabetes Metab. J. 2013, 37, 349-357. [CrossRef] [PubMed] 
18. Lee, H.S.; Lee, S.S.; Hwang, I.Y.; Park, Y.J.; Yoon, S.H.; Han, K.; Son, J.W.; Ko, S.H.; Park, Y.G.; Yim, H.W.; et al. Prevalence, awareness, treatment and control of hypertension in adults with diagnosed diabetes: The Fourth Korea National Health and Nutrition Examination Survey (KNHANES IV). J. Hum. Hypertens. 2013, 27, 381-387. [CrossRef] [PubMed]

19. Ong, K.L.; Cheung, B.M.; Man, Y.B.; Lau, C.P.; Lam, K.S. Prevalence, awareness, treatment, and control of hypertension among United States adults 1999-2004. Hypertension 2007, 49, 69-75. [CrossRef] [PubMed]

20. Islam, S.A.; Seo, M.; Lee, Y.S.; Moon, S.S. Association of periodontitis with insulin resistance, beta-cell function, and impaired fasting glucose before onset of diabetes. Endocr. J. 2015, 62, 981-989. [CrossRef] [PubMed]

21. Gennaro, G.; Claudino, M.; Cestari, T.M.; Ceolin, D.; Germino, P.; Garlet, G.P.; de Assis, G.F. Green tea modulates cytokine expression in the periodontium and attenuates alveolar bone resorption in type 1 diabetic rats. PLoS ONE 2015, 10, e0134784. [CrossRef] [PubMed]

22. Gadagi, J.S.; Chava, V.K.; Reddy, V.R. Green tea extract as a local drug therapy on periodontitis patients with diabetes mellitus: A randomized case-control study. J. Indian Soc. Periodontol. 2013, 17, 198-203. [PubMed]

23. Hirasawa, M.; Takada, K.; Makimura, M.; Otake, S. Improvement of periodontal status by green tea catechin using a local delivery system: A clinical pilot study. J. Periodontal. Res. 2002, 37, 433-438. [CrossRef] [PubMed]

24. Chava, V.K.; Vedula, B.D. Thermo-reversible green tea catechin gel for local application in chronic periodontitis: A 4-week clinical trial. J. Periodontol. 2013, 84, 1290-1296. [CrossRef] [PubMed]

25. Hattarki, S.A.; Pushpa, S.P.; Bhat, K. Evaluation of the efficacy of green tea catechins as an adjunct to scaling and root planing in the management of chronic periodontitis using PCR analysis: A clinical and microbiological study. J. Indian Soc. Periodontol. 2013, 17, 204-209. [CrossRef] [PubMed]

26. Kudva, P.; Tabasum, S.T.; Shekhawat, N.K. Effect of green tea catechin, a local drug delivery system as an adjunct to scaling and root planing in chronic periodontitis patients: A clinicomicrobiological study. J. Indian Soc. Periodontol. 2011, 15, 39-45. [CrossRef] [PubMed]

27. Maruyama, T.; Tomofuji, T.; Endo, Y.; Irie, K.; Azuma, T.; Ekuni, D.; Tamaki, N.; Yamamoto, T.; Morita, M. Supplementation of green tea catechins in dentifrices suppresses gingival oxidative stress and periodontal inflammation. Arch. Oral Biol. 2011, 56, 48-53. [CrossRef] [PubMed]

28. Hrishi, T.; Kundapur, P.; Naha, A.; Thomas, B.; Kamath, S.; Bhat, G. Effect of adjunctive use of green tea dentifrice in periodontitis patients-A randomized controlled pilot study. Int. J. Dent. Hyg. 2015. [CrossRef] [PubMed]

29. Kaur, H.; Jain, S.; Kaur, A. Comparative evaluation of the antiplaque effectiveness of green tea catechin mouthwash with chlorhexidine gluconate. J. Indian Soc. Periodontol. 2014, 18, 178-182. [CrossRef] [PubMed]

30. Renaud, J.; Nabavi, S.F.; Daglia, M.; Nabavi, S.M.; Martinoli, M.G. Epigallocatechin-3-gallate, a promising molecule for Parkinson's disease? Rejuvenation Res. 2015, 18, 257-269. [CrossRef] [PubMed]

31. Yiannakopoulou, E. Targeting oxidative stress response by green tea polyphenols: Clinical implications. Free Radic. Res. 2013, 47, 667-671. [CrossRef] [PubMed]

32. Asahi, Y.; Noiri, Y.; Miura, J.; Maezono, H.; Yamaguchi, M.; Yamamoto, R.; Azakami, H.; Hayashi, M.; Ebisu, S. Effects of the tea catechin epigallocatechin gallate on Porphyromonas gingivalis biofilms. J. Appl. Microbiol. 2014, 116, 1164-1171. [CrossRef] [PubMed]

33. Zhao, L.; La, V.D.; Grenier, D. Antibacterial, antiadherence, antiprotease, and anti-inflammatory activities of various tea extracts: Potential benefits for periodontal diseases. J. Med. Food 2013, 16, 428-436. [CrossRef] [PubMed]

34. Hosokawa, Y.; Hosokawa, I.; Shindo, S.; Ozaki, K.; Matsuo, T. (-)-Epigallocatechin-3-gallate inhibits CC chemokine ligand 11 production in human gingival fibroblasts. Cell Physiol. Biochem. 2013, 31, 960-967. [CrossRef] [PubMed]

35. Desjardins, J.; Grenier, D. Neutralizing effect of green tea epigallocatechin-3-gallate on nicotine-induced toxicity and chemokine (C-C motif) ligand 5 secretion in human oral epithelial cells and fibroblasts. J. Investig. Clin. Dent. 2012, 3, 189-197. [CrossRef] [PubMed]

36. Bedran, T.B.L.; Spolidorio, D.P.; Grenier, D. Green tea polyphenol epigallocatechin-3-gallate and cranberry proanthocyanidins act in synergy with cathelicidin (LL-37) to reduce the LPS-induced inflammatory response in a three-dimensional co-culture model of gingival epithelial cells and fibroblasts. Arch. Oral Biol. 2015, 60, 845-853. [CrossRef] [PubMed] 
37. Makimura, M.; Hirasawa, M.; Kobayashi, K.; Indo, J.; Sakanaka, S.; Taguchi, T.; Otake, S. Inhibitory effect of tea catechins on collagenase activity. J. Periodontol. 1993, 64, 630-636. [CrossRef] [PubMed]

38. Bae, J.; Park, P.S.; Chun, B.Y.; Choi, B.Y.; Kim, M.K.; Shin, M.H.; Lee, Y.H.; Shin, D.H.; Kim, S.K. The effect of coffee, tea, and caffeine consumption on serum uric acid and the risk of hyperuricemia in Korean Multi-Rural Communities Cohort. Rheumatol. Int. 2015, 35, 327-336. [CrossRef] [PubMed]

39. Bezerra, J.P.; da Silva, L.R.; de Alvarenga Lemos, V.A.; Duarte, P.M.; Bastos, M.F. Administration of high doses of caffeine increases alveolar bone loss in ligature-induced periodontitis in rats. J. Periodontol. 2008, 79, 2356-2360. [CrossRef] [PubMed]

40. Kamagata-Kiyoura, Y.; Ohta, M.; Cheuk, G.; Yazdani, M.; Saltzman, M.J.; Nakamoto, T. Combined effects of caffeine and prostaglandin E2 on the proliferation of osteoblast-like cells (UMR106-01). J. Periodontol. 1999, 70, 283-288. [CrossRef] [PubMed]

41. Loria, D.; Barrios, E.; Zanetti, R. Cancer and yerba mate consumption: A review of possible associations. Rev. Panam. Salud Publica 2009, 25, 530-539. [CrossRef] [PubMed]

42. Song, H.B.; Lee, S.A. Socioeconomic and lifestyle factors as risks for suicidal behavior among Korean adults. J. Affect. Disord. 2016, 197, 21-28. [CrossRef] [PubMed]

(C) 2016 by the authors; licensee MDPI, Basel, Switzerland. This article is an open access article distributed under the terms and conditions of the Creative Commons Attribution (CC-BY) license (http://creativecommons.org/licenses/by/4.0/). 